\title{
Symmetric All-Quinone Aqueous Battery
}

\section{Citation}

Tong, L., Y. Jing, R. Gordon, \& M. Aziz. (2019). Symmetric All-Quinone Aqueous Battery. ACS Applied Energy Materials 2, no. 6: 4016-4021.

\section{Permanent link}

http://nrs.harvard.edu/urn-3:HUL.InstRepos:42482311

\section{Terms of Use}

This article was downloaded from Harvard University's DASH repository, and is made available under the terms and conditions applicable to Open Access Policy Articles, as set forth at http:// nrs.harvard.edu/urn-3:HUL.InstRepos:dash.current.terms-of-use\#OAP

\section{Share Your Story}

The Harvard community has made this article openly available.

Please share how this access benefits you. Submit a story.

Accessibility 


\title{
Symmetric All-Quinone Aqueous Battery
}

\author{
Liuchuan Tong, ${ }^{\nabla, \dagger}$ Yan Jing, ${ }^{\nabla, \dagger}$ Roy G. Gordon, ${ }^{\dagger, t} *$ and Michael J. Aziz ${ }^{\dagger} *$
}

${ }^{\nabla}$ Liuchuan Tong and Yan Jing contributed equally.

$\ddagger$ Department of Chemistry and Chemical Biology, Harvard University, Cambridge, MA 02138,

USA

$\$$ John A. Paulson School of Engineering and Applied Sciences, Harvard University, Cambridge,

MA 02138, USA

* To whom correspondence should be addressed: gordon@chemistry.harvard.edu (Roy G.

Gordon); maziz@harvard.edu (Michael J. Aziz).

Abstract: Here we report a symmetric all-quinone aqueous battery based entirely on Earthabundant elements that uses a naturally-occurring dye as the redox-active material in both positive and negative electrodes. We demonstrated a symmetric all-quinone cell with $1.04 \mathrm{~V}$ of open circuit voltage, $163 \mathrm{mAh} / \mathrm{g}$ of capacity, and 100 cycles at $10 \mathrm{C}$ with $100 \%$ of depth of discharge. The use of the same quinone in a symmetric setup expands the repertoire of inexpensive redox active materials for aqueous rechargeable batteries, and the simple cell design will enable optimizations toward safe, cheap, lightweight, and flexible electronics in future.

Key words: Symmetric, metal-free, quinone, three-states, aqueous, proton battery.

Lithium-ion batteries continue to dominate portable electronics and electric vehicles markets for its high energy density/specific energy. ${ }^{1}$ However, combustible electrolytes and expensive cathodes pose safety and cost concerns to consumers. ${ }^{2}$ Further cost reduction is expected to be limited after decades of development. ${ }^{3}$ Next generation energy storage devices call for safe, cheap, resource-abundant and flexible batteries. ${ }^{2}{ }^{4}$ Rechargeable batteries with cost-effective redox active materials and aqueous electrolytes can potentially meet these requirements. ${ }^{5}$ Currently, the lead-acid battery (LAB) has the largest market share among aqueous batteries and continues to be attractive for its wide availability and competitive price. ${ }^{6}$ However, in addition to the obvious environmental concerns of lead, ${ }^{7}$ the LAB has fundamental chemistry challenges during cycling. Sulfuric acid electrolyte participates in the redox chemistry, and sulfation, a buildup of lead sulfate crystals on electrodes over cycling, incurs mechanical stress and penalizes cycle life significantly. ${ }^{8}$ Therefore the LAB can be cycled only with a shallow depth of discharge (DoD), and a tradeoff between effective energy density and cycle life is inevitable. Nickel-metal hydride aqueous batteries suffer from similar volume expansion problems and some use expensive rareearth metals in the anode. ${ }^{9}$ Emerging aqueous rechargeable lithium/sodium-ion batteries utilize electrode materials (particularly the cathodes) similar to those used in non-aqueous 
lithium/sodium-ion batteries, but they have less than half of the voltage $(<1.5 \mathrm{~V})$ of their nonaqueous counterparts. ${ }^{10}$ penalizing their economics.

Organic electrode materials, which consist of earth-abundant elements such as $\mathrm{C}, \mathrm{H}$, and $\mathrm{O}$ and are synthesized at a much lower temperature $\left(<200{ }^{\circ} \mathrm{C}\right)$ than their inorganic counterparts $\left(>500{ }^{\circ} \mathrm{C}\right),{ }^{4}$ are becoming promising candidates for the next generation of sustainable energy storage devices. ${ }^{11}$ Quinones are a class of organic molecules that are ubiquitous in nature and known to participate in a fast, two-electron redox process via a proton-coupled electron transfer (PCET) mechanism. ${ }^{12}$ Quinones have been explored in the context of non-aqueous solid batteries ${ }^{13}$ and aqueous flow batteries. ${ }^{14}$ More recently, Liang et al. investigated quinones as anodes in aqueous solid batteries. ${ }^{15}$ However, cathodes remained inorganic, e.g. lead dioxide, lithium magnesium oxide/lithium cobalt oxide, nickel oxyhydroxide, etc. We here report the use of a single quinone molecule as both negative and positive electrode material in a symmetric cell. The concept of a symmetric cell system has been proposed in various battery systems for its simplicity in design, and has been demonstrated in both non-aqueous flow battery ${ }^{16}$ and solid-electrode battery communities. ${ }^{17,18}$ The redox-active materials in symmetric cells could be organics, ${ }^{17}$ inorganics ${ }^{18}$ or organometallic complexes. ${ }^{19}$ In order to build a symmetric cell, the redox-active material must have at least three stable oxidation states. For example, inorganic metal complexes have multiple oxidation states. ${ }^{18}$ Organic molecules often delocalize charges in extended $\pi$-electron systems such as porphyrins, ${ }^{20}$ or have bipolar functional groups, ${ }^{17}$ but these functional groups are usually incompatible with aqueous systems.

Motivated by recent success in the development of anthraquinone-based negative electrolyte materials for high performance aqueous flow batteries, ${ }^{14,21-23}$ we explore the third oxidation state of a fused anthraquinone, alizarin, in a single-compound battery. Alizarin, historically used as a natural dye, exists in abundance in plants of the madder genus and was the first natural dye to be synthesized at industrial scale. ${ }^{24}$ When two quinone motifs fuse together (Figure 1a), three oxidation states exist in one single anthraquinone molecule. During charging, the center para-quinone motif can be reduced into para-hydroquinone on the negative side to form fused-hydroquinone, and the right ortho-hydroquinone motif can be oxidized into ortho-quinone on the negative side to form fused-quinone. Conversely, during discharging, the fusedhydroquinone and fused-quinone would comproportionate back to alizarin. Therefore, compared to LABs, these PCET processes in a solid battery may lead to a relatively smaller volume change of redox active materials and induce less mechanical stress in electrodes as a result of minimal changes in molecular structure. 
a

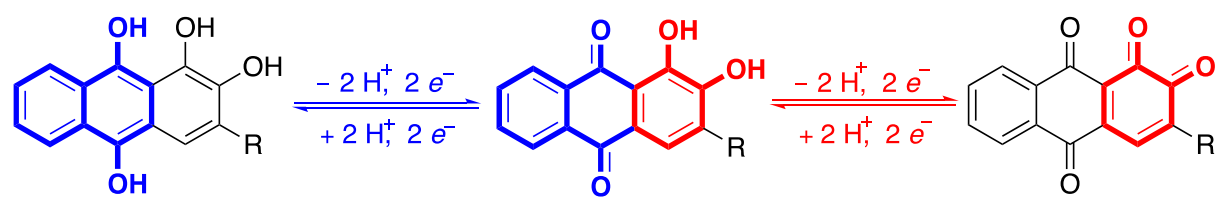

$\mathrm{R}=-\mathrm{H},-\mathrm{SO}_{3} \mathrm{H}$
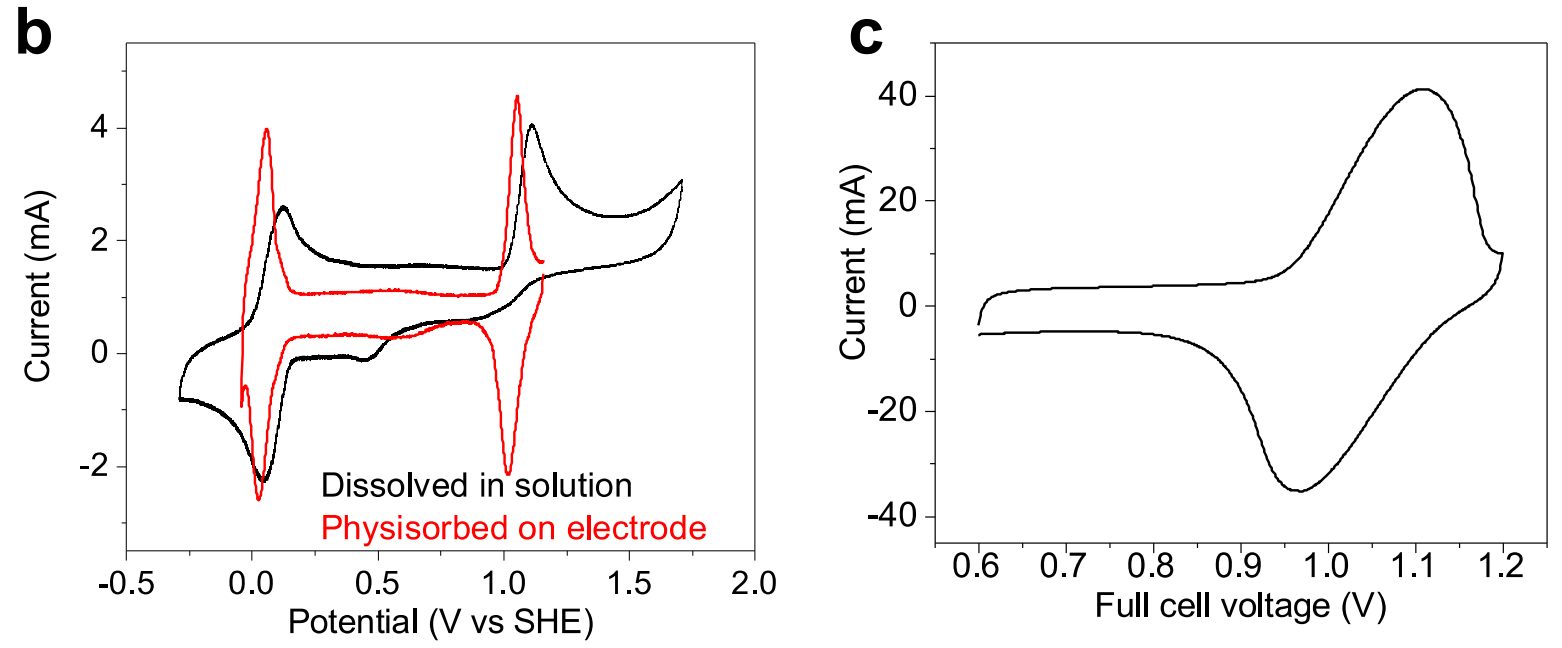

Figure 1. PCET working mechanism and corresponding cyclic voltammetry (CV) curves. (a) alizarin (center) accepting two electrons and two protons to become fully reduced (left), or donating two electrons and two protons to become fully oxidized (right) in redox reactions. (b) $\mathrm{CVs}$ of alizarin sulfonate $\left(\mathrm{R}=\mathrm{SO}_{3}{ }^{-}\right)$dissolved in solution and physisorbed on carbon paper electrode in $1 \mathrm{M} \mathrm{H}_{2} \mathrm{SO}_{4}$, scan rate: $10 \mathrm{mV} / \mathrm{s}$. Positive current is oxidative. The scanning range is $-0.25 \mathrm{~V}$ to $1.75 \mathrm{~V}$ vs SHE for alizarin sulfonate dissolved in solution; $-0.05 \mathrm{~V}$ to $1.20 \mathrm{~V}$ vs SHE for alizarin sulfonate physisorbed on electrode. (c) Full cell CV curve from the symmetric full cell on flexible carbon cloth.

To investigate the redox activity of the system, a cyclic voltammetry (CV) study of a soluble alizarin, alizarin sulfonate, was undertaken. As expected, the low-potential redox couple showed excellent redox activity near $0 \mathrm{~V}$ vs standard hydrogen electrode (SHE); however, no reduction signal was observed for the high-potential redox couple, which exhibited an abnormally high oxidation peak (Figure 1b). Such behavior was not specific to alizarin, but was also observed for other fused quinones, including quinizarin and other fused quinone derivatives. In previous work, Carretero-González et al. discovered that a reversible $\mathrm{CV}$ at high potential can be obtained on a working electrode with microcavities filled with alizarin and carbon particles, ${ }^{25}$ but it was unclear what caused the difference in the observed redox behavior.

To probe whether the oxidation product is unstable, we chemically synthesized the oxidized alizarin in its tetra-one form (fused-quinone), and found it to be stable in aqueous solution (Figure S1, S2). In alizarin sulfonate, only at high $\mathrm{CV}$ scan rates (> $5 \mathrm{~V} / \mathrm{s}$ ) did the high-potential reduction peak appear and become more symmetric with its oxidation peak, indicating that the oxidized form appears only to be stabilized in the solid state (as an adsorbate or insoluble solid) (Figure S2, S3). It was hypothesized that the alizarin undergoes two separate one-electron 
processes during oxidation, and in solution the intermediate radical may diffuse away and cause subsequent degradation before it is oxidized to the stable tetra-one form (Scheme S1) ${ }^{26}$ Therefore, we reasoned that improved electrochemical reversibility at high potential is feasible if the electrontransfer kinetics of the oxidation process can be enhanced by maintaining intimate contact between the molecules and the conducting material. Indeed, when alizarin sulfonate was pre-adsorbed onto carbon paper (Scheme S2), and used directly as the working electrode, a reversible redox process was observed for the high potential part of the molecule even at the slow CV scan rate of $10 \mathrm{mV} / \mathrm{s}$ (Figure 1b). We attribute the improved kinetics and stability to the ability to rapidly complete the two-electron transfer between the carbon electrode and adsorbed alizarin sulfonate. The adsorbed alizarin sulfonate displayed two sets of reversible and symmetrical redox peaks.

The difference in potentials provides opportunity to build a $1 \mathrm{~V}$ battery within the $1.23 \mathrm{~V}$ thermodynamic water stability window. Solubilizing groups, which are usually attached on quinones for solubility improvement in flow batteries, were found to be irrelevant to the observed behavior, and unfunctionalized, insoluble alizarin displayed the same behavior when adsorbed on carbon paper (Figure S4). As a proof-of-concept of symmetric quinone redox couple, a pseudocapacitor was assembled using two sheets of high surface area flexible carbon cloth (Spectracarb ${ }^{\mathrm{TM}}$ 2225 Type 900 Activated Carbon Fabric) with adsorbed alizarin on both terminals. The full cell voltage was $1.04 \mathrm{~V}$ at 50\% SOC (Figure 1c). This flexible symmetric aqueous quinone pseudocapacitor was successfully subjected to 200 consecutive deep charge-discharge cycles (Figure S5).

a
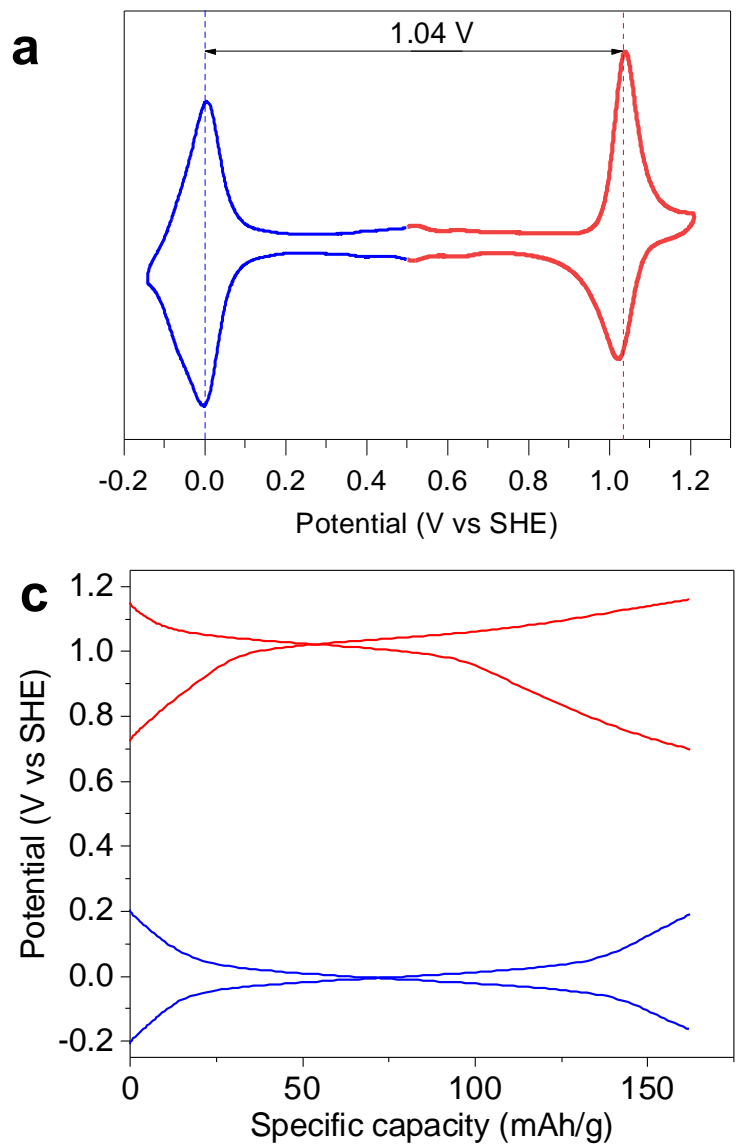

b
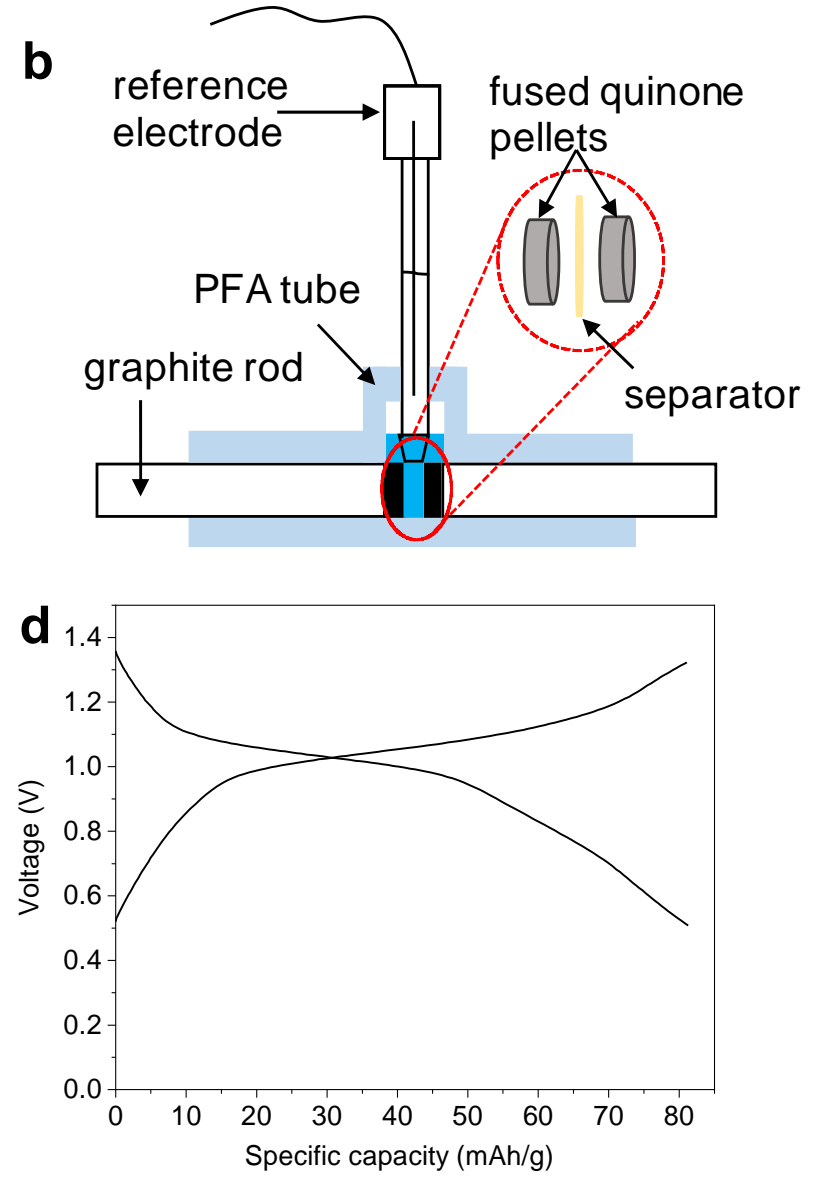

Figure 2. Electrochemical characterization of alizarin-based electrode. (a) The CV curve of ballmilled composite in $1 \mathrm{M} \mathrm{H}_{2} \mathrm{SO}_{4}$. The ball-milled alizarin/ketjen black/graphite composite (mass 
ratio: $\mathrm{w} / \mathrm{w} / \mathrm{w}=3: 6: 1)$ was first suspended in acetone with a concentration of $10 \mathrm{mg} / \mathrm{mL}$ then drop casted on glassy carbon working electrode. Scan rate: $100 \mathrm{mV} / \mathrm{s}$. (b) Schematics of alizarin-based three-electrode full cell. (c) Voltage profiles of alizarin as positive (red) and negative (blue) materials, respectively. (d) The full cell voltage $(1.0 \mathrm{~V})$ of alizarin-based balanced cell. The specific capacity is based on the total quantity of alizarin active material on both electrodes. The theoretical capacity of alizarin is $223.3 \mathrm{mAh} / \mathrm{g}$.

Encouraged by the performance of the alizarin-based flexible pseudo-capacitor, for which the physio-adsorbed redox active material was limited to only a few mono-layers on the carbon surface, we sought to increase the loading of active material to achieve a practically useful energy density. Therefore, commercial alizarin powder was ball-milled with Ketjenblack (Figure S6) to mimic in a battery electrode the intimate contact between redox-active material and electron conducting material apparent in the pseudo-capacitor. The mixture exhibited the expected redox activity in CV (Figure 2a). We assembled a three-electrode symmetric cell using nominally identical pellets of the composite as both positive and negative electrode, separated by a hydrophilic porous separator (Celgard ${ }^{\circledR}$ coated PP 3401). An Ag/AgCl reference electrode was immersed in the $1 \mathrm{M}$ sulfuric acid electrolyte near the separator (Figure 2b). This setup allowed us to monitor the performance of both electrodes simultaneously and independently. Figure $2 \mathrm{c}$ shows the charge-discharge voltage profiles of both electrodes at a C-rate of $10 \mathrm{C}\left(10 \mathrm{~mA} / \mathrm{cm}^{2}\right)$ with a clear voltage plateau of $1 \mathrm{~V}$ for high potential and $0 \mathrm{~V}$ for low potential; these are in excellent agreement with the $\mathrm{CV}$ measurement. The full cell voltage profile of this symmetric cell was plotted in Figure $2 \mathrm{~d}$. It shows an average voltage of $1 \mathrm{~V}$ and accessed a specific capacity of 81.5 $\mathrm{mAh} / \mathrm{g}$, which is based on total quantity of alizarin on both electrodes, and is $73.0 \%$ of the theoretical value.
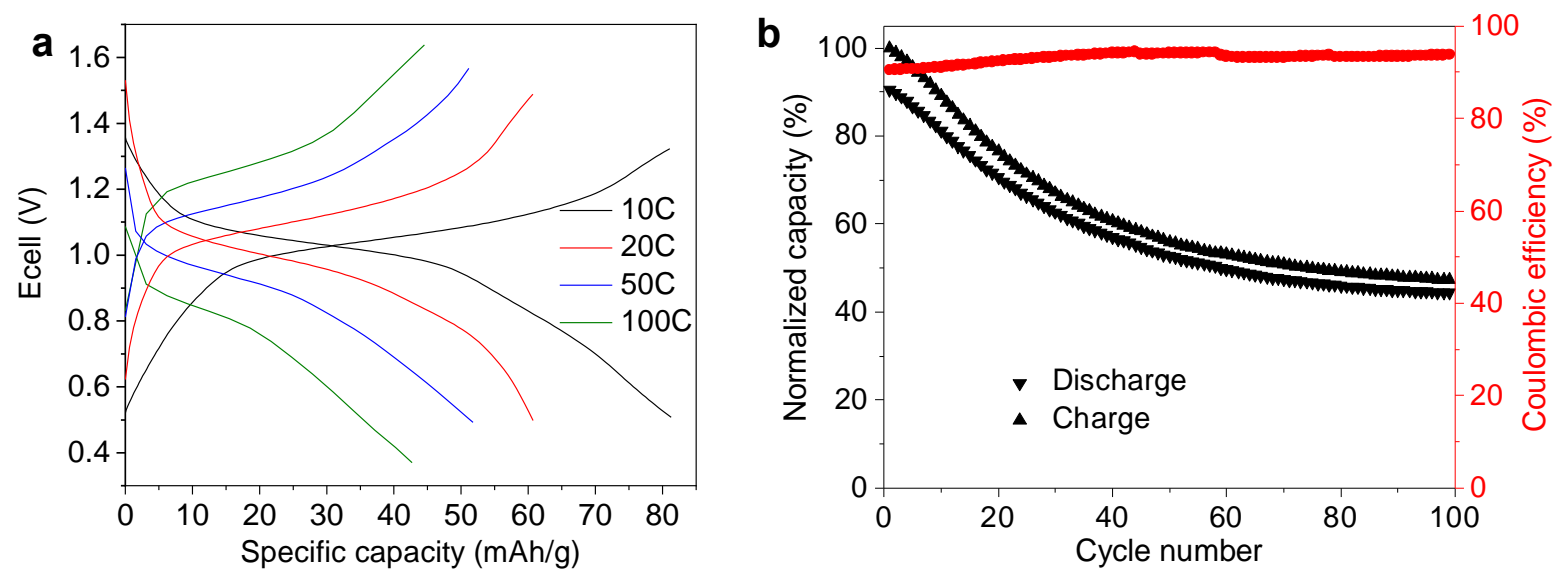

Figure 3. Symmetric alizarin cell performance. (a) The rate performance of the symmetric alizarin cell at 10,20,50, and 100C. $1 \mathrm{C}=223.3 \mathrm{~mA} / \mathrm{g}$. The specific capacity is based on the total quantity of alizarin active material on both electrodes. (b) Cycling stability of the alizarin cell at 10C. The negative electrode is the capacity-limiting side. The positive electrode is the non-capacity-limiting side.

The electrochemical performance of the symmetric alizarin cell was further evaluated. Figure 3a showed the specific capacities and voltage profiles at different current rates. When the total quantity of alizarin active material on both electrodes was considered, the discharge capacities 
were $81.5,60.5,51.5$, and $42.5 \mathrm{mAh} / \mathrm{g}$, and the mid-point discharge voltages are $1.00,0.95,0.87$, and $0.74 \mathrm{~V}$ when the cell was cycled at 10,20, 50, and 100C, respectively. The overpotential increases and the capacity decreases with increasing current density. Figure $3 \mathrm{~b}$ shows the results of cycling of the alizarin-based symmetric full cell at 10C; the negative side is capacity-limiting. This unoptimized cell retained $47 \%$ of its initial capacity after 100 cycles of full charge and discharge, and the Coulombic efficiency stabilized at $95 \%$.

To gain insight into the capacity loss of the full cell, cycling performance of each terminal was evaluated independently with respect to the reference electrode. We found that the positive terminal capacity decayed at a much higher rate than the anode capacity when cycled at 10C (Figure S7). The ${ }^{1} \mathrm{H}$ NMR spectra of cycled alizarin from the negative terminal remained unchanged, whereas decomposition was observed in alizarin samples from positive terminal after 200 cycles (Figure S8, S9). In addition to the possible radical decomposition as discussed above, the highly electron-deficient oxidized alizarin is subject to decomposition via Michael addition, as observed in other high potential quinones. ${ }^{27,28}$

a
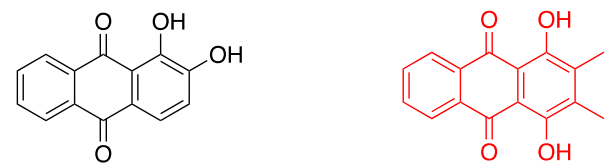

b
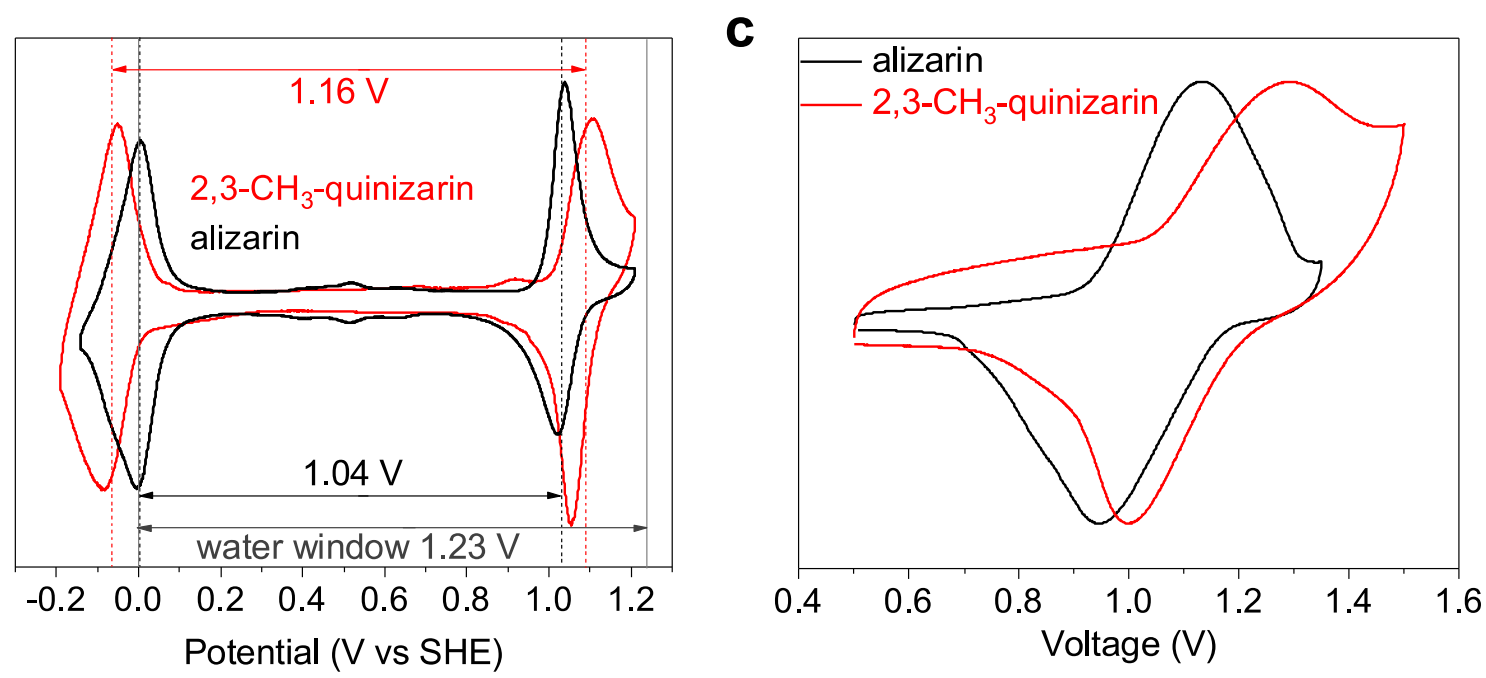

Figure. 4 Alternative symmetric quinone. (a) Structures of alizarin and 2,3-dimethyl-quinizarin (2,3- $\mathrm{CH}_{3}$-quinizarin). (b) $\mathrm{CV}$ of $2,3-\mathrm{CH}_{3}$-quinizarin compared to alizarin. Scan rate: $100 \mathrm{mV} / \mathrm{s}$. 2,3- $\mathrm{CH}_{3}$-quinizarin (red) has a broader voltage window compared to alizarin (black). (c) The full cell voltage of 2,3- $\mathrm{CH}_{3}$-quinizarin symmetric cell compared to alizarin symmetric cell.

The use of organic material permits the modification of molecular structure to fine tune the desired properties. A preliminary study into the synthesis of other fused quinone derivatives suggests that it is possible to increase the cell voltage and decrease the molecular decomposition rate. For instance, Figure 4a showed the structure of another modified fused quinone, 2,3-dimethylquinizarin (2,3- $\mathrm{CH}_{3}$-quinizarin). The molecule was specifically designed to prevent the attack from Michael addition by nucleophiles on the electrophilic $\mathrm{C}-\mathrm{H}$ positions on the oxidized fused-quinone form. The methyl group is hypothesized to protect the nucleophilic decomposition through steric 
hindrance. To confirm the presumed stability enhancement, we chemically synthesized oxidized 2,3-dimethyl-quinizarin and its unprotected precursor, oxidized quinizarin. The oxidized quinones were stirred with $1 \mathrm{M}$ sulfuric acid overnight and analyzed by ${ }^{1} \mathrm{H}$ NMR (Figure S10, S11). As expected, hydroxide addition onto the unprotected quinizarin was observed; whereas the protected 2,3- $\mathrm{CH}_{3}$-quinizarin remained unchanged with only a trace amount of self-discharged $2,3-\mathrm{CH}_{3}-$ quinizarin due to its highly oxidative nature, confirming the protective nature of the two methyl groups. When compared to alizarin, 2,3-dimethyl-quinizarin has an extended potential window $(1.16 \mathrm{~V})$ (Figure 4b). The reduction potential for the negative part decreased by $50 \mathrm{mV}$ and that of the positive part increased by $70 \mathrm{mV}$, resulting in $120 \mathrm{mV}$ higher full cell voltage than alizarin (Figure 4c). Furthermore, we examined the high potential cycled 2,3- $\mathrm{CH}_{3}$-quinizarin electrode by ${ }^{1} \mathrm{H}$ NMR, confirming that most species are oxidized 2,3- $\mathrm{CH}_{3}$-quinizarin (Figure $\mathrm{S} 12$, S13). It is also possible to pair different quinones in an asymmetric setup. The (-) alizarin $\left|1 \mathrm{M} \mathrm{H}_{2} \mathrm{SO}_{4}\right| 2,3-$ $\mathrm{CH}_{3}$-quinizarin (+) showed a much-improved life time that retained $55 \%$ of capacity after 500 cycles (Figure S14). Whereas the methylation of quinizarin increases the cycle life by blocking the Michael addition, the remaining sources of capacity fade are not clear at this early stage, in which the microstructure of the composite and the macrostructure of the cell and its operation have not been optimized. Varying the strength of adsorption by tailoring the chemical properties of the carbon or the quinone may change the rates of semiquinone production and decomposition. The current situation may be analogous to that of 2,6-dihydroxy-anthraquinone which decomposed at a rate of $\sim 5 \%$ /day when it was first introduced; ${ }^{29}$ subsequent chemical modifications $^{21,23}$ and operating condition modifications ${ }^{30}$ have reduced the fade rate by orders of magnitude.

In summary, we report a symmetric quinone-acid cell with $1.04 \mathrm{~V}$ of voltage and $163 \mathrm{mAh} / \mathrm{g}$ of specific capacity at 10C (See Table S1 for comparison with other aqueous batteries). The alizarin-based symmetric quinone-acid cell retains $45 \%$ of its capacity after 100 cycles with $100 \%$ of DoD. Our metal-free SQAB is potentially environmentally benign. The natural abundance and cheap commercial source promise its low cost when produced at large scale. We demonstrated with 2,3-dimethyl quinizarin that other fused quinone derivatives can also be used for symmetric quinone-acid batteries. The new chemistry and simple cell design provide a new platform for future optimization that can enable substantial cost-reduction and rapid engineering development. Further optimization of fused quinones with improved reduction potential and stability, and cell engineering of electrode composition and morphology can further improve the performance of the battery.

\section{Supporting Information}

Materials and methods; Synthesis of oxidized alizarin; Electrochemistry of physisorbed alizarin; Electrode material preparation; Synthesis of quinizarin and derivatives and corresponding electrochemistry; and Tabulated comparison of aqueous batteries.

\section{Acknowledgments}

This work was partially funded through US Department of Energy ARPA-E Award DEAR0000767, U.S. Department of Energy Contract No. DE-AC05-76RL01830 through PNNL Subcontract No. 428977, and the Massachusetts Clean Energy Technology Center. We thank Xian Gong for performing SEM imaging, Dr. Yunlong Ji for assistance with chemical synthesis, Dr. Qing Chen for assistance with electrochemical measurement and Dr. Michael Marshak for helpful discussions. 


\section{References}

1. Zubi, G.; Dufo-López, R.; Carvalho, M.; Pasaoglu, G., The lithium-ion battery: State of the art and future perspectives. Renewable and Sustainable Energy Reviews 2018, 89, 292-308.

2. Armand, M.; Tarascon, J. M., Building better batteries. Nature 2008, 451, 6.

3. Few, S.; Schmidt, O.; Offer, G. J.; Brandon, N.; Nelson, J.; Gambhir, A., Prospective improvements in cost and cycle life of off-grid lithium-ion battery packs: An analysis informed by expert elicitations. Energy Policy 2018, 114, 578-590.

4. Larcher, D.; Tarascon, J. M., Towards greener and more sustainable batteries for electrical energy storage. Nat. Chem. 2015, 7 (1), 19-29.

5. Beck, F.; Rüetschi, P., Rechargeable batteries with aqueous electrolytes. Electrochimica Acta 2000, 45, 16.

6. Chen, H. Y.; Li, A. J.; Finlow, D. E., The lead and lead-acid battery industries during 2002 and 2007 in China. Journal of Power Sources 2009, 191 (1), 22-27.

7. van der Kuijp, T.; Huang, L.; Cherry, C. R., Health hazards of China's lead-acid battery industry: a review of its market drivers, production processes, and health impacts. Environmental Health 2013, 12 (61), 10.

8. Zou, X., Kang, Zongxuan, Shu, Dong, Liao, Yuqing, Gong, Yibin, He, Chun, Hao, Junnan, Zhong, Yayun, Effects of carbon additives on the performance of negative electrode of lead-carbon battery. Electrochimica Acta 2015, 151, 89-98.

9. Rodrigues, L. E. O. C.; Mansur, M. B., Hydrometallurgical separation of rare earth elements, cobalt and nickel from spent nickel-metal-hydride batteries. Journal of Power Sources 2010, 195 (11), 3735-3741.

10. Kim, H.; Hong, J.; Park, K. Y.; Kim, H.; Kim, S. W.; Kang, K., Aqueous rechargeable Li and $\mathrm{Na}$ ion batteries. Chem. Rev. 2014, 114 (23), 11788-827.

11. Liang, Y.; Yao, Y., Positioning Organic Electrode Materials in the Battery Landscape. Joule 2018, 2 (9), 1690-1706.

12. Quan, M.; Sanchez, D.; Wasylkiw, M. F.; Smith, D. K., Voltammetry of Quinones in Unbuffered Aqueous Solution: Reassessing the Roles of Proton Transfer and Hydrogen Bonding in the Aqueous Electrochemistry of Quinones. Journal of American Chemical Society 2007, 129, $12847-12856$.

13. Jing, Y.; Liang, Y.; Gheytani, S.; Yao, Y., Cross-conjugated oligomeric quinones for high performance organic batteries. Nano Energy 2017, 37, 46-52.

14. Huskinson, B., Marshak, M. P., Suh, C., Er, S., Gerhardt, M. R., Galvin, C. J., Chen, X., Aspuru-Guzik, A., Gordon, R. G., Aziz, M. J., A metal-free organic-inorganic aqueous flow battery. Nature 2014, 505 (7482), 195-8.

15. Liang, Y., Jing, Y., Gheytani, S., Lee, K-Y., Liu, P., Facchetti, A., Yao, Y., Universal quinone electrodes for long cycle life aqueous rechargeable batteries. Nat. Mater. 2017, 16, 8.

16. Potash, R. A.; McKone, J. R.; Conte, S.; Abruña, H. D., On the benefits of a symmetric redox flow battery. Journal of The Electrochemical Society 2016, 163 (3), A338-A344.

17. Suga, T.; Sugita, S.; Ohshiro, H.; Oyaizu, K.; Nishide, H., p- and n-Type bipolar redoxactive radical polymer: Toward totally organic polymer-based rechargeable devices with variable configuration. Adv. Mater. 2011, 23 (6), 751-4.

18. Gao, H.; Goodenough, J. B., An aqueous symmetric sodium-ion battery with NASICONstructured $\mathrm{Na}_{3} \mathrm{MnTi}\left(\mathrm{PO}_{4}\right)_{3}$. Angew. Chem. Int. Ed. 2016, 55 (41), 12768-72. 
19. Suttil, J. A.; Kucharyson, J. F.; Escalante-Garcia, I. L.; Cabrera, P. J.; James, B. R.; Savinell, R. F.; Sanford, M. S.; Thompson, L. T., Metal acetylacetonate complexes for high energy density non-aqueous redox flow batteries. Journal of Materials Chemistry A 2015, 3 (15), 7929-7938.

20. Ma, T.; Pan, Z.; Miao, L.; Chen, C.; Han, M.; Shang, Z.; Chen, J., Porphyrin-based symmetric redox-flow batteries towards cold-climate energy storage. Angew. Chem. Int. Ed. 2018, 57 (12), 3158-3162.

21. Ji, Y., Goulet, M-A., Pollack, D. A., Kwabi, D. G., Jin, S., De Porcellinis, D., Kerr, E. F., Gordon, R. G., Aziz, M. J., A phosphonate-functionalized quinone redox flow battery at nearneutral $\mathrm{pH}$ with record capacity retention rate. Adv. Energy Mater. 2019, 9, 1900039.

22. Gerhardt, M. R.; Tong, L.; Gómez-Bombarelli, R.; Chen, Q.; Marshak, M. P.; Galvin, C. J.; Aspuru-Guzik, A.; Gordon, R. G.; Aziz, M. J., Anthraquinone derivatives in aqueous flow batteries. Advanced Energy Materials 2017, 7, 1601488.

23. Kwabi, D. G.; Lin, K.; Ji, Y.; Kerr, E. F.; Goulet, M.-A.; De Porcellinis, D.; Tabor, D. P.; Pollack, D. A.; Aspuru-Guzik, A.; Gordon, R. G.; Aziz, M. J., Alkaline quinone flow battery with long lifetime at $\mathrm{pH}$ 12. Joule 2018, 2, 1907.

24. Bien, H. S.; Stawitz, J.; Wunderlich, K., Anthraquinone Dyes and Intermediates. In Ullmann's Encyclopedia of Industrial Chemistry, Wiley-VCH: 2000.

25. Carretero-González, J.; Castillo-Martínez, E.; Armand, M., Highly water-soluble threeredox state organic dyes as bifunctional analytes. Energy Environ. Sci. 2016, 9, 3521-3530.

26. Yamamoto, N.; Kubozono, T.; Kinoshita, Y., Mechanism for oxidative decomposition of anthraquinone dye with hydrogen peroxide. Journal of Oleo Science 2001, 50 (6), 507-513.

27. Yang, B., Hoober-Burkhardt, L., Wang, F., Surya Prakash, G. K., Narayanan, S. R., An inexpensive aqueous flow battery for large-scale electrical energy storage based on water-soluble organic redox couples. Journal of the Electrochemical Society 2014, 161, A1371-A1380.

28. Tabor, D.; Gómez-Bombarelli, R.; Tong, L.; Gordon, R. G.; Aziz, M. J.; Aspuru-Guzik, A., Theoretical and experimental investigation of the stability limits of quinones in aqueous media: implications for organic aqueous redox flow batteries. ChemRxiv: 10.26434/chemrxiv.6990053.v2 2018.

29. Lin, K.; Chen, Q.; Gerhardt, M. R.; Tong, L.; Kim, S. B.; Eisenach, L.; Valle, A. W.; Hardee, D.; Gordon, R. G.; Aziz, M. J.; Marshak, M. P., Alkaline quinone flow battery. Science 2015, 349 (6255), 1529.

30. Goulet, M.-A.; Tong, L.; Pollack, D. A.; Tabor, D. P.; Kwan, E. E.; Aspuru-Guzik, A.; Gordon, R. G.; Aziz, M. J., Extending the lifetime of organic flow batteries via redox state management. J. Am. Chem. Soc. 2019, DOI: 10.1021/jacs.8b13295. 
Table of Content (TOC)<smiles>O=C1c2ccccc2C(=O)c2cc3c(=O)c(=O)c(=O)c3cc21</smiles>
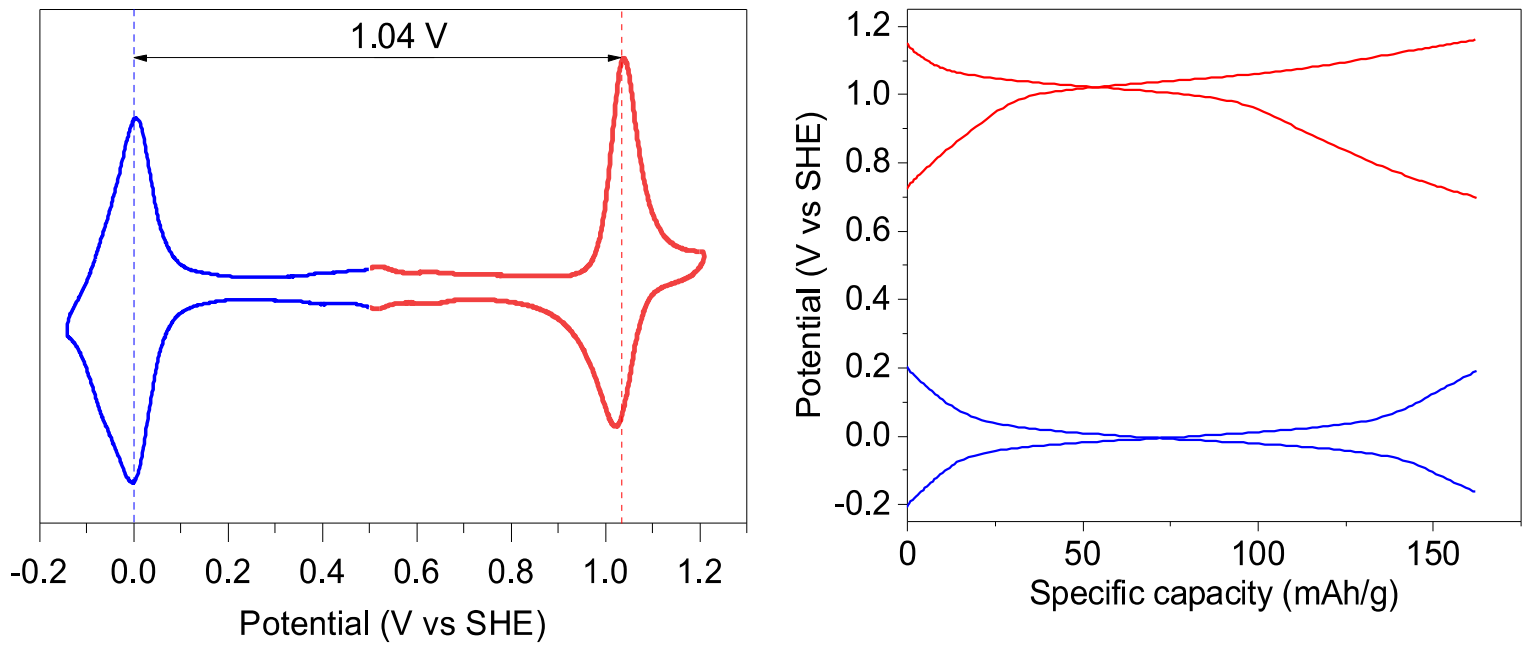